\title{
Field Method Research for Leak-off Coefficient Analysis Using Instantaneous Shut-in Pressure
}

\author{
Cai Bo ${ }^{1,2}$, Ding Yunhong ${ }^{1,2}$, Lu Yongjun ${ }^{2}$, Shen $\mathrm{Hua}^{3}$ and Yang Zhenzhou ${ }^{2}$ \\ 1. Petroleum Exploration \& Development, PetroChina Research Institute, Beijing 100083, China \\ 2. Petroleum Exploration \& Development-Lang fang Branch, PetroChina Research Institute, Langfang 065007, China \\ 3. Huabei Oilfield Company, PetroChina, Renqiu 062250, China
}

Received: June 24, 2013 / Accepted: August 26, 2013 / Published: January 31, 2014.

\begin{abstract}
The accurate monitor and prediction of fracturing pressure for formation is very important to hydraulic fracturing treatment operation, but whether hydraulic fracturing is successful or not, the fracturing fluid plays a very important role, leak-off coefficient is the most leading parameters of fracturing fluids. Mini-frac test was the most commonly used tools for leak-off coefficient analysis, but it has the shortcoming of time-consuming and costly that can not meet the requirement of the production. The main purpose of this paper is to introduce a simple and convenient leak off coefficient analysis method with more inexpensive and time-saving than former methods. Based on ISIP (instantaneous shut-in pressure) method, a new field method of leak off coefficient field analysis model was presented. According to twice ISIP of the fracturing treatment in field operation, therefore, fluid leak off coefficient and formation characteristic can be studied quickly and reliably. More than 40 wells were fractured using this field method. The results show that average liquid rates of post-fracturing was $20 \mathrm{~m}^{3} / \mathrm{d}$ which double improvement compared with the past treatment wells. It had an important role for fracturing treatments in low permeability reservoirs, the new model for real time analysis and adjust is successful used in field application.
\end{abstract}

Key words: Hydraulic fracturing, fracturing fluid, leak off coefficient, instantaneous shut-in pressure, field method, post-fracturing performance.

\section{Introduction}

Hydraulic fracturing treatments were pumped into permeable formations with permeable fluids. This means that as the fracturing fluid was being pumped into the formation, a certain proportion of this fluid is being lost into formation as fluid leak off. The accurate understanding of leak off coefficient of fracturing fluid is an important guidance to hydraulic fracturing design and field operation. As the fracturing fluid enters the pay zone, the influence of fluid's leak-off on the fracturing pressure and fracturing geometry must be considered. Carter was the first to try to quantify fluid leak off and defined the leak off volume in terms of an overall leak off coefficient but considered mainly

Corresponding author: Cai Bo, Dr., research fields: oil and gas development engineering. E-mail: boocai123@126.com. depend on theoretical formulations which can not be used in real-time filed operation [1]. Hubbert-Willis formula can not predict the fracturing leak off of the permeable zone [2, 3]. Ren developed a leak off coefficient model for post-fracturing tight gas wells according to core filtration experiment and retical model of forcing fracture closure, and the mathematic formula above mentioned for leak off coefficient was applied widely, while which can not interpret leak off coefficient in real-time operation leading to the formula can not estimate the fracture geometry as quick as possible. In order to put forward a simple and convenient leak off coefficient analysis method for field application; based on ISIP (instantaneous shut-in pressure) and fluid mechanics, a new method of leak off coefficient analysis was presented. According to 
twice ISIP of fracturing treatment in field operation, fluid leak off coefficient and formation characteristic can be studied quickly and reliably making fracturing treatment more scientific. More than 40 wells were fractured using this field method. The results show that average liquid rates of post-fracturing was $20 \mathrm{~m}^{3} / \mathrm{d}$ which double improvement compared with the past treatment wells. And it was proven that the new model for hydraulic fracturing treatment is greatly improved.

\section{The Model of Leak off Coefficient}

The filter loss rate is high in the early stage, and becomes low with time and is almost a fixed value in late stage. The fracturing fluid loss decreases from fracture start to fracture end and the invasion damage zone mainly concentrates on the fracture-start [4], Fig. 1 shows leak off regions in artificial fractures during the treatment. The principle of this model: generally speaking, ISIP in second time is higher than first time, the reason is that pore pressure around the wellbore happens to change variously as the fracturing fluid leak off enters the pay zone [5]. The change of pore pressure affects the stress-state and induces increasing stress around the wellbore. The bigger of two ISIP difference is, the more leak off in formation of filtration will occur $[6,7]$. As the artificial fracture hydraulic fractures extends to the poor property formation, the stress of the regional high can also cause leak off serious.

According to the mass conservation principle volume,

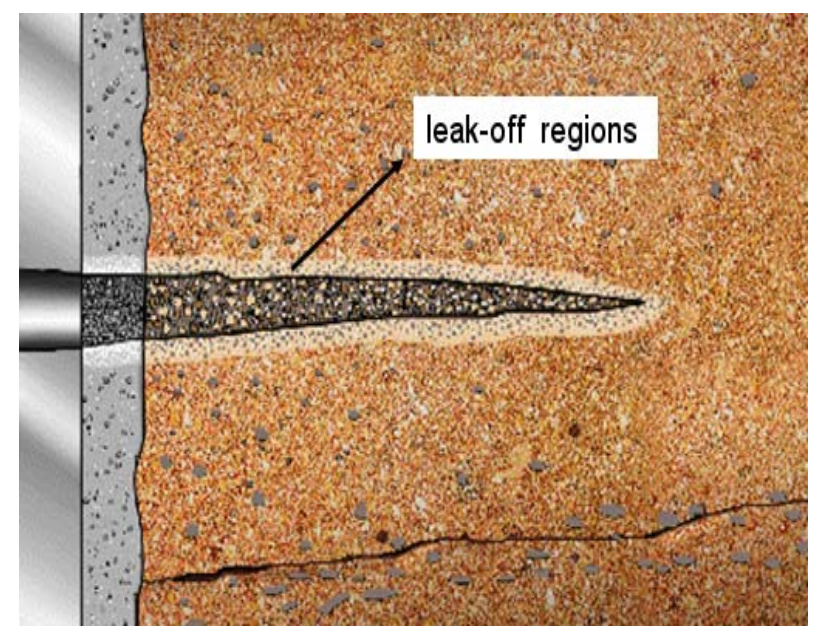

Fig. 1 Leak off regions in artificial fractures. the volume pumped into well subtract the leak off loss equal the volume of hydraulic fracture [8]. The equation of the changed leak off coefficient $C_{t}$ equation can be given by:

$$
C_{t}=\frac{1}{3.28 \sqrt{t-t_{0}}}\left[\frac{1}{C^{\prime}}\left(\frac{\operatorname{ISIP}(t)+P_{H}}{\operatorname{ISIP}\left(t_{0}\right)+P_{H}}-1\right)\right]^{\frac{1}{c^{\prime \prime}}}
$$

where, $t$ is the pumping time, $t_{o}$ is the shut-in at one point time, $C^{\prime}$ and $C^{\prime \prime}$ are the fracture geometry index, respectively, for PKN model, $C^{\prime}$ is 0.203 , $C^{\prime \prime}$ is 0.472 ; for KGD model, $C^{\prime}$ is $0.197, C^{\prime \prime}$ is $0.468 ; P_{H}$ is the pumping pressure. Eq. (1) shows that the leak off coefficient for the formation is exponential to ISIP. Using Eq. (1), the curve of different leak off coefficient along with different ISIP time can be expressed by Fig. 2. From the Fig. 2, it can be seen that the leak off coefficient of fluid can be obtained easily and audio-visually, so the fracturing treatment can be adjusted in real-time field operation by the treatment policymaker.

\section{Field Application Results and Discussion}

For the natural fracture sand formation of the well 130 at 2,506 $\mathrm{m}$ depth, the average permeability is 0.1 $\mathrm{md}$, the average effective porosity is $8.9 \%$, the original formation pore pressure of $25.1 \mathrm{MPa}$. The tensile strength is $8.2 \mathrm{MPa}$, and Poisson ratio is 0.24 , we take two ISIP during the treatment, the first ISIP is $6.7 \mathrm{MPa}$ with the second is $8.9 \mathrm{MPa}$, According to Eq. (1), the ratio of two ISIP reach 1.32 and the estimated leak off

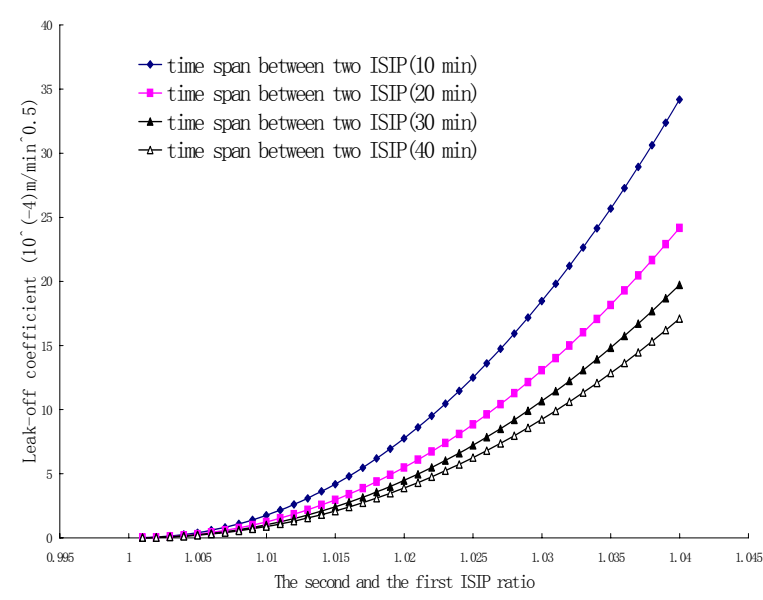

Fig. 2 Leak off coefficient vs. ISIP. 
coefficient is $1.5 \times 10^{-3} \mathrm{~m} / \mathrm{min}^{0.5}$, this means the leak off volume is very large, analysis of the causes are the existence of natural fractures with poor physical property in far wellbore areas, so filtrate measures, high velocity fluid and more fluid volume were taken, these series measures make the operation successfully. Oilfield application shows that twice ISIP method can be effectively used to describe the leak off contribution of the change around the wellbore caused by fracturing fluid [9]. More than 40 wells were fractured using above methods.

Fig. 3 shows that average liquid rates of post-fracturing was $20 \mathrm{~m}^{3} / \mathrm{d}$ which double improvement compared with the past treatment wells. It had an important role for fracturing treatments in low permeability reservoirs. The new model for real time analysis and adjust is successful used in field application.

In generally, mini-frac test can be used to determine formation filtration coefficient, but the cost is too high and the formation would be caused additional damage. The method mentioned in this paper is simple, does not increase more liquid volume (compared with the mini-frac), will not cause adverse consequences of increased reservoir damage. Fluid leak off coefficient and formation characteristic can be studied quickly and reliably.

\section{Conclusions}

(1) The leak off coefficient performances differently for different fracturing fluid system. This is exactly the reason for the premature screen out during the treatment if the design is ill-conceived, especially in the natural fissure formation.

(2) Traditionally, formation filtration coefficient was dominated by mini-frac test but the cost is too high and the formation would be caused additional damage, therefore, fluid leak off coefficient and formation characteristic must be studied quickly and reliably for field application.

(3) According to the mass conservation principle volume and based on function of instantaneous shut-in

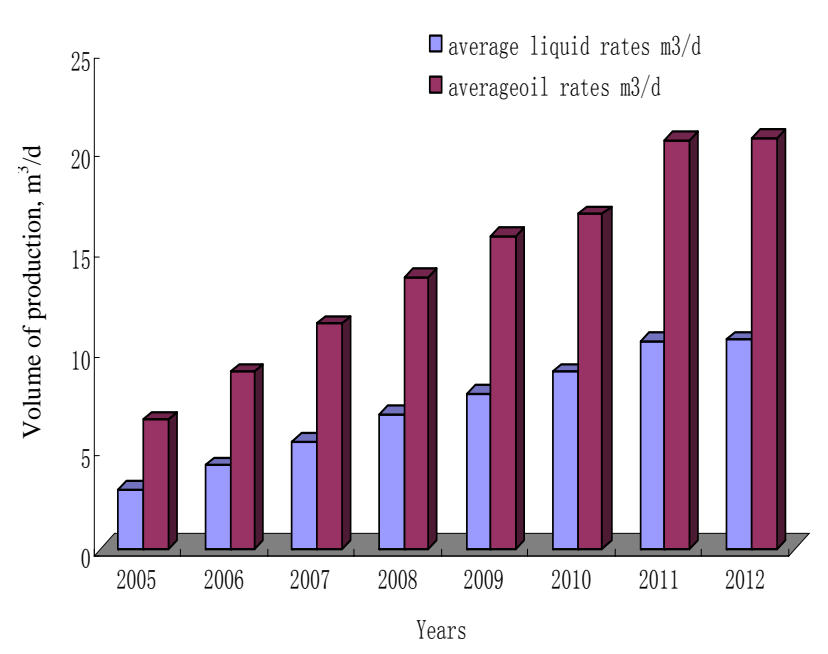

Fig. 3 Average liquid rates of post-fracturing from 2005 to 2012.

pressure, a new method of leak off coefficient analysis field model was presented. According to twice ISIP of the fracturing treatment in field operation, the simulation calculation shows the new model is very convenient and practical and can be used in the fracturing treatment operation in real time.

(4) More than 40 wells were fractured using this field method. The results show that average liquid rates of post-fracturing was $20 \mathrm{~m}^{3} / \mathrm{d}$ which double improvement compared with the past treatment wells. It had an important role for fracturing treatments in low permeability reservoirs, the new model for real time analysis and adjust is successful used in field application.

\section{Acknowledgments}

The authors thank RIPED for partial support of this work (100083), and thank RIPED-Lang fang for its permission to publish this (065007), the authors also thank Huabei Oil Field Corporation, PetroChina (062550), for provides test site.

\section{References}

[1] R. Carter, Derivation of the general equation for of optimum fluid characteristic for fracture extension, Drilling and Production Practice 5 (1957) 261-269.

[2] T. Yi, M. Peden, Comprehensive model of fluid loss in hydraulic fracturing, SPE Production \& Facilities 9 (4) (1994) 267-272. 
[3] M. Econmides, T. Martin, Modern Fracturing Enhancing Natural Gas Production, Gulf Publishing Co. Press, Houston, USA, 2008.

[4] B. Cai, X. Wang, X. Wang, Mathematical study of fracture face skin in hydraulic fractures, Journal of China University of Mining \& Technology 40 (6) (2011) 938-942. (in Chinese)

[5] K. Adegbola, C. Boney, Effect of fracture face damage on well productivity, in: International Symposium and Exhibition on Formation Damage Control paper Conference, Lafayette, Louisiana, 2002, pp. 1-10.

[6] J. Diego, J. Economides, The optimization of the productivity index and the fracture geometry of a stimulated well with fracture face and choke skins, in:
International Symposium and Exhibition on Formation Damage Control paper Conference, Lafayette, Louisiana, 2002, pp. 11-18.

[7] B. Haimson, C. Faihurst, Hydraulic fracturing in porous-permeable materials, Journal of Petroleum Technology 21 (7) (1969) 811-817.

[8] P. Multalik, Case history of sequential and simultaneous fracturing of the Barnett shale in Parker County, in: SPE Annual Technical Conference and Exhibition, Denver, Sept. 21-24, 2008, pp. 1-10.

[9] T. Jiang, Y. Xu, Z. Li, X. Wang, B. Cai, A new method of selective separate layer fracturing by delivering seal balls in pad stage and its application, Natural Gas Industry 29 (9) (2009) 88-90. 